\title{
Looking through glass walls: Women engineers in Portugal ${ }^{\text {is }}$
}

\author{
a School of Psychology, University of Minho, Campus de Gualtar, 4710-057 Braga, Portugal \\ b Institute of Education, University of Minho, Campus de Gualtar, 4710-057 Braga, Portugal \\ c Lisbon University Institute (ISCTE-IUL), CIS-IUL, Av. das Forças Armadas, 1649-026 Lisboa, Portugal \\ d School of Psychology, Massey University, Palmerston North 4442, New Zealand
}

Luísa Saavedra $^{\mathrm{a}, *}$, Alexandra M. Araújo ${ }^{\mathrm{b}}$, João Manuel de Oliveira ${ }^{\mathrm{c}}$, Christine Stephens ${ }^{\mathrm{d}}$

\section{A R T I C L E I N F O}

\section{Available online $\mathrm{xxxx}$}

\begin{abstract}
S Y N O P S I S
Women face significant barriers adjusting to the professional culture of engineers, which is strongly connected to hegemonic masculinity. This study aims to investigate how Portuguese female engineers negotiate their identities and subjective positions in a relational environment marked by this dominant form of masculinity. Drawing on the analyses of interviews with 39 female engineers, we focused on the ways women position themselves in this professional culture and cope with the gender regimes they experience in this environment. Using a Foucauldian Discourse Analysis, we identified an essentialist and dichotomous discourse about what it is to be a man or a woman in engineering and the following four themes: disguising differences with similarities, assuming differences by valuing femininity, assuming differences and inequalities, and maintaining limits and respect. The participants in this study seemed to be stuck in a prison with transparent and unbreakable glass walls, which risks their personal and relational well-being.
\end{abstract}

(c) 2014 Elsevier Ltd. All rights reserved.

\section{Introduction}

Women's access to the labour market in recent decades has not encouraged women to choose engineering careers, nor to believe in their own capacity for the job. In fact, the number of women in engineering education and careers is still very low in Western countries, despite efforts to improve the proportion of women engineers (Mills, Gill, Sharp, \& Franzway, 2011). Moreover, gender issues or gender discrimination are not perceived as significant (Kelan, 2007), favouring behaviours of opposition or indifference by both female and male engineers (Mills et al., 2011).

In Portugal, statistics show a slight decrease of women's representation in higher education in engineering: in 2000, $28.3 \%$ of engineering graduate students were women, while in 2009, this rate was only $24.79 \%$ (GPEARI, 2009). Despite the

\footnotetext{
Fis Funded by the Project "Women in Science, Engineering and Technologies: The leaky pipeline effect" (PIHM/GC/0035/2008).

* Corresponding author.
}

attention to this topic in social science literature (Bouville, 2008; Brotman \& Moore, 2008; Fassinger, Scantlebury, \& Richmond, 2004), a strong masculisation of professional contexts and organisational cultures is still prevalent (Lee \& Faulkner, 2010).

Engineering is not the only case of a professional culture marked by hegemonic masculinity, as the same situation has been observed in other highly qualified, prestigious professional cultures such as advocacy, magistracy (e.g. Marques, 2011; Martin, Reynolds, \& Keith, 2002) and surgery (e.g. Cassell, 2000; Grant, Robinson, \& Muir, 2004), where inequalities are evident despite men and women's equal qualifications (Connell, 2002; Leon, 1994). Surgery, one of the few medical specialities where women are a minority in European countries (Marques, 2011), is marked by a masculine culture that values being 'tough', invulnerable, and totally dedicated to work (Cassell, 2000). Due to this construction of surgery identities and practices, many women think of surgery as an unrealistic, although highly desirable, career choice (Glynn \& Kerin, 2010). In addition, the required intense and long traineeships, as well as a busy lifestyle 
afterwards (Glynn \& Kerin, 2010), may affect accomplishments in family life (Marques, 2011). Sexual harassment is also a common expression of masculinised surgery work environments, influencing women's decisions to drop out of internships (Hinze, 2004). Lawyering resembles this situation: the ethos of competition and long working hours seem to reflect masculine values and lifestyles. In this masculinised culture, a judge is expected to be impartial, authoritarian, and emotionally dehumanised, characteristics of hegemonic masculinity (Freenan, 2008). Measuring women against this standard limits their career ascension as they struggle with adherence to 'male' norms (Watts, 2009, p. 512), in terms of their psychological characteristics, public presentation, language and conversations with co-workers (Faulkner, 2009a,b). Additionally, women in these professional cultures tend to deny the experience of discrimination or other difficult situations (Nogueira, 2009). Therefore, women's access to 'masculinised' professions has not led to changes in the prevailing organisational environment: women tend to regulate their behaviour following the prevailing norms of masculinity, and men tend to act in a way that reinforces the existing regime, showing aggressiveness, ambition, strength, and self-reliance (Connell, 2002).

Some theories have sought to explain women's underrepresentation and the oppression they are submitted to in masculinised work environments. According to the model of gender symbolic asymmetry, the cultural organisation of representations of gender divides the world between men considered a symbolical universal point of reference - and women - presented in a condition of alterity and whose historical anchorage binds existence to the family and domestic sphere (Amâncio \& Oliveira, 2006). This alterity is also mentioned by Simone de Beauvoir (1989) as a consequence of the androcentric system that prevails in society.

Wendy Faulkner (2000) discusses gender in/authenticity to describe the in/congruence of gender and engineering identities of men and women engineers. Her work focuses on the way engineering is perceived and experienced as an authentic choice for men, but not a genuine one for women. Furthermore, the gendered dualism of 'the technical'/'the social' in organisational and professional cultures is not shown in actual practice, as engineering is a heterogeneous and networked practice that relies simultaneously on technical and social skills. Regardless of its heterogeneous nature (Faulkner, 2007), including several specialities and job opportunities, engineering has been constructed for more than two decades as a male-dominated practice in a way that profoundly marks this profession as symbolically masculine (Oldenziel, 1999). Such symbolism seems to be based on an association between technology, machines and science (Faulkner, 2001; Wajcman, 2000) reinforcing hegemonic masculinity (Connell, 1995), as mentioned in several feminist studies (e.g., Faulkner, 2007; Frehill, 2009; Marques, 2011). Consequently, engineering as a profession provides a potentially fruitful site for the study of gender practices, precisely because it 'represents a particularly visible instantiation of the still durable cultural equation between masculinity and technology' (Faulkner, 2000, p. 761).

Furthermore, female engineers are confronted with difficulties regarding their simultaneous positioning both as a woman and a professional, experiencing a so-called double bind dilemma (Jamieson, 1995; Kendall, 2000; Peterson, 2010). In this type of dilemma, women who wish to assert their femininity using psychological characteristics that are usually attributed to women, such as empathy and cooperation, are considered less competent or professionally ineffective. On the other hand, if women display assertiveness, self-reliance, and ambition, like men traditionally do, they are regarded as less feminine. In addition, technical competency - an important dimension of the construction of a professional identity in engineering - creates a new double bind for women because professional competence in this domain evidences masculine attributes (Kendall, 2000). Consequently, when women act according to a work ideal, their behaviour may not be rewarded because it is in contradiction with expectations for genderappropriate behaviour (Peterson, 2010).

In engineering workplace cultures, women place themselves and are placed by others in a way that makes them visible as women and invisible as engineers, limiting the recognition of their working capabilities and undermining their self-confidence and self-esteem (Faulkner, 2007, 2009b). Given this theoretical and empirical framework, the goal of this paper is to investigate the way Portuguese women in engineering professions deal with the contradictory positions of gender and profession (cf. Nogueira, 2009). How do they position themselves in their relations with male and female co-workers regarding their competence and/or femininity? Do they resort to regulating discourses when confronted with hegemonic masculinity or, in some cases, use discourses of resistance? These issues are particularly important considering that hegemony is in continuous conflict with resistance. This work can help to understand if there are movements to change the prevailing organisational culture, or instead, if gendered identities persist in contexts marked by gender tensions. In addition, we aim to understand if the amount of work experience could contribute to the differentiation of discursive practices.

\section{Participants, sampling and analytic procedures}

The participants were 39 female engineers from north and central Portugal, including 20 women who had recently joined the job market (ages between 24 and 34 years old) and 19 engineers with ten or more years of professional experience (ages between 35 and 62 years old). Defining these two distinct groups of women allows for study of whether their professional experience influences their perception of the professional culture in which they work. Respondents were female engineers in public and private industry careers (such as software companies, road companies, or quality and environmental control), with various educational backgrounds in engineering: Chemical Engineering $(n=5)$, Metallurgical Engineering $(n=1)$, Mechanical Engineering $(n=3)$, Textile Engineering ( $n=1)$, Geological Engineering $(n=4)$, Engineering and Industrial Management $(n=2)$, Civil Engineering ( $\mathrm{n}=17$ ), Physics Engineering $(\mathrm{n}=1)$, Computer Engineering $(\mathrm{n}=2)$ and Electrotechnical Engineering $(\mathrm{n}=3)$. Three participants accumulated functions as teachers in higher education. The mean participant age in the younger group was 29.2 ( $S D=3.09$ ), and the mean participant age in the group with more professional experience was 46.6 $(\mathrm{SD}=8.10)$.

Sampling was done using the snowball technique, reaching potential participants that matched the study's criteria 
regarding age and years of professional experience. Participants were informed about the goals of the study, and confidentiality and anonymity were guaranteed. Women who agreed to participate signed an informed consent form and allowed the interviews to be audio recorded. Interviews took place at the participants' homes or at the researchers' offices and were conducted by two researchers with training in psychology and qualitative methodologies. Questions focused on difficulties that participants may have experienced when adjusting to a male-dominated environment and the strategies they used to cope with these challenges. Questions aimed to explore difficulties related to the respondents' interactions with male and female co-workers, which were at the centre of analysis in this study.

A Foucauldian Discourse Analysis (Arribas-Ayllon \& Walkerdine, 2007; Willig, 2003, 2008) was conducted to analyse the interviews. According to this methodological approach, language is not an expression of a cognitive representation, but a means through which objects, experiences and realities are constructed (Parker, 1992, 1999; Willig, 2003). This analysis focused on the ways respondents resort to socially available discourses, following the implications of Foucault's work on discourse, resistance, subjectification and power (Foucault, 1984, 1985, 1988).

Despite the absence of rigid steps or stages, the data analysis proceeded through the identification of discursive constructions (or themes that organise the studied object) (Willig, 2003, 2008), or discourses (Foucault, 1971) as rules and systems of a particular body of knowledge. It also included an analysis of subjective positions and subjectifications, aiming to understand the particular practices and strategies through which subjects self-regulate (Arribas-Ayllon \& Walkerdine, 2007; Foucault, 1988; Willig, 2008). After selecting the excerpts that focused on relationships with male and female co-workers and subordinates, we identified different ways of approaching these relations and named them according to their different underlying meanings.

\section{The construction of difference between men and women}

Reading and analysis of the transcripts resulted in the identification of a central discourse that reflected an essentialist and dichotomous vision of what it is to be a male and a female through the description of invariable characteristics attributed to each of the sexes. However, within this discourse, we identified several themes that construct ways of coping with "difference". We designated these themes as follows: (1) Disguising differences with similarities, (2) Assuming differences by valuing femininity, (3) Assuming differences and inequalities, and (4) Maintaining limits and respect.

The "Disguising differences with similarities" theme presents a strategy of devaluing female characteristics compared with characteristics traditionally presented as masculine. In the subjective position "Assuming the differences by valuing femininity", a reverse strategy is used: women highlight and value psychological attributes that are considered feminine, although they do not underestimate masculine characteristics. In the third theme, "Assuming differences and inequalities", women present differences openly, but they do not value either the masculine or the feminine characteristics. Finally, the "Maintaining limits and respect" theme presents several technologies of the body to deal with perceived differences between women and men that are supported mainly by a dress code as well as a way of talking. Common to all four themes is a rigorous and highly aware self-discipline of the body (even more evident in the discursive strategy "Maintaining limits and respect"), combined with a series of technologies of the self (Foucault, 1988) that aim to regulate thoughts and actions. However, the particular means of resorting to these mechanisms creates a different subjectification of what it is to be a female engineer in interaction with male engineers, female colleagues and subordinates.

\section{Disguising differences with similarities}

Firstly, it is important to highlight that this is the theme most used by the respondents. Women engineers who resorted to this theme explicitly mentioned a preference for working with men, with whom relationships are regarded as trouble-free:

'I think that it is very good to work with men. I think that, perhaps, it is more difficult to work with women. I feel men are more predictable, more open, they do not give big surprises, let's just say that.'

[Female chemical engineer, 55 years old, participant 1]

These women also elaborate on their own expression of traditional masculine characteristics:

'Perhaps because I also have a more rational side, more yang, more masculine, so I identify myself with their way of thinking.'

[Industrial manager and engineer, 39 years old, participant 8]

These explanations result from the identification with characteristics that are positively associated with masculinity and suggest a rejection of the more fragile expressions of femininity. Thus, rationality - a crucial characteristic for engineers - emerges as a masculine attribute, conveying the traditional association between the masculine ideal and rationality (Saavedra \& Nogueira, 2006). This association is supported by a masculinised definition of the profession, as suggested in various studies (Brotman \& Moore, 2008; Fassinger et al., 2004; Lee \& Faulkner, 2010), and involves normative adjustment of the interviewee's subjectivity to the norms of masculinity in engineering. Such a concern is expressed in the way these women in engineering careers become accustomed to men's conversations and do not feel offended by their aggressive content, which suggests a submission to masculine normativity:

'I blend easily in conversations, those everyday chats... the conversations about football. Their language has never affected me much, as well... There's a very masculine language, isn't there? I'm not offended by certain words or certain jargon.'

[Female metallurgist, 43 years old, participant 4]

Furthermore, these women seem to feel more protected and integrated in the group: 
'I relate to men much better than to women, I feel much more protected, I feel more integrated in the teams.'

[Female geological engineer, 39 years old, participant 9]

The word 'protected' might be used as an expression of benevolent sexism (Glick \& Fiske, 2001), matching the romantic idea of gallantry expressed in the princess metaphor (Martínez Reina \& Cea, 2006) or in the traditional image of female fragility and masculine domination. By offering their female co-workers protection, men avoid women's affirmative capacity and threats to installed power. This reinforces women's submission and protects men's hegemonic masculinity. Finally, another statement might shed some light on the reasons these women feel more protected and integrated in teams composed mostly of men. When questioned about her relationships with other women, one of the interviewees responded:

'They are probably more competitive, because they try to set out their own domain, their own interaction zone, so I think that there is much more competitiveness among women than between women and men.'

[Female metallurgist, 43 years old, participant 4]

This last excerpt seems to suggest that women need to create 'their own domain', probably because they feel they can't compete with their male colleagues. As a result, they seem to 'choose' to compete with other women and therefore feel more easily integrated into male-dominated teams due to the lack of perceived competition. Furthermore, competition between women, which has little coherence with the image of a conventional feminine identity, appears to be a consequence of hegemonic masculinity and therefore an adaptation strategy to this professional culture. Such adherence to competition among women inhibits women from resorting to a collective strategy. Moreover, alliance with men leads to a social construction of these professionals as 'exceptional women' who deny characteristics that are considered feminine and who steer away from female groups. Even references to personal appearance are presented as something that comes naturally and with little thought. There seems to be a denial of the characteristics women consider as feminine, and femininity is lived as a risk for adjustment in the workplace similar to what Simone de Beauvoir (1989) described as identity mutilation. In addition, although these women adopt assertive and self-confident behaviours that are clearly associated with men and valued in male-dominated professional cultures, it is not so clear that they will achieve the recognition they strive for (e.g., Faulkner, 2009b; Peterson, 2010). In this double bind, these participants seem like they are looking for professional recognition at the expense of losing their femininity.

\section{Assuming differences by valuing femininity}

The central assumption of this theme is the valorisation of female-appropriate characteristics. It is important to underline that this discourse is very rare among the participants in this study. Women highlighted the way their male colleagues value characteristics that effectively correspond to the traditional view of femininity:

'I think they have a lot of respect for women, because women are more conventional, less adventurous, more organised.'

[Female civil engineer, 27 years old, participant 1]

Femininity is valued by the respondents particularly regarding the traditional domains of the exercise of femininity, namely social interactions and the management of everyday life:

'They're time-consuming activities, very demanding, that call for consensus. I think that women have a better capacity for reaching consensus.'

[Female metallurgist engineer, 43 years old, participant 4]

This appeal to an essentialist perspective of femininity seems to give power to women by highlighting the positive aspects of feminine characteristics as defended by Carol Gilligan (1982). On the other hand, displaying these characteristics might be a risk for women's adjustment to their workplace and for their careers, as they may be regarded as less competent or professionally effective, again experiencing a double bind dilemma. In order to preserve their feminine identity and to cope with hegemonic masculinity, these women are likely to blend several technologies, using more feminine attributes and at the same time a more masculine physical presentation, as we shall see in the next discourse.

\section{Maintaining limits and respect}

This theme describes a careful use of language and personal presentation by the participants resulting in constant self-examination and surveillance of other people's reactions to their performance:

'I try not to address any employee in a familiar way, even if I get along quite well with that employee. I always try to keep my distance. It is not that I think I'm superior to anyone because I'm an engineer, never, but I feel that this separation is needed in order to avoid transposing reasonable interpersonal boundaries.'

[Female geological engineer, 30 years old, participant 5]

We might ask what these 'reasonable interpersonal boundaries' represent for these women. Are these boundaries an issue of protecting their professional territory, or do these boundaries define the personal and sexualised realm? Perhaps we are dealing with both concerns, as seen when participants began to talk about their physical presentation:

'Because I want to be respected and deserve that respect and, in order to do so, I obviously do not come here in a mini-skirt and high-heeled shoes.'

[Female geological engineer, 39 years old, participant 9]

Indeed, in order to avoid eroticism and sexuality in social relations with male colleagues, as well as sexual harassment, these women may choose to masculinise their appearance, as 
mentioned in a more explicit or implicit way throughout various interviews:

"But in terms of harassment, it's not easy... Every day there is something."

[Female civil engineer, 32 years old, participant 12]

The same participant, in response to a question about the strategies she uses to deal with sexual harassment, answered:

"Yes, clearly, my way of dressing: I think that I have never worn a dress or a skirt for work, or a low neckline. The way I sit down, how I talk...”.

The exercise of female invisibility, through a less feminine physical presentation, is not only a means of accentuating the visibility of women's professionalism (Jorgensen, 2002; Kendall, 2000; Peterson, 2010) but also a strategy to avoid sexual harassment. The resulting normative physical appearance may be understood as a consequence of hegemonic masculinity (Connell, 1995). Research has already offered examples of such norms of masculinity. António Marques (2011), in a study with professionals (female magistrates, female surgeons, and female taxi drivers) who were also employed in predominantly masculine environments, found that the masculinisation of visual appearance allows these female professionals to become asexual, less desirable figures, or closer to the masculine ideal. In these professional cultures, femininity is associated with eroticism and sexuality, as mentioned by Oliveira and Amâncio (2002).

Engineering is not the only profession in which physical appearance is relevant. However, in this specific case, the women's central concern does not seem to be about presenting a good image of their company or even complying with the company's dress codes. These women in engineering professions are much more concerned with implementing gender-conscious techniques of self-discipline as they submit to norms of masculinity. These techniques promote a desexualising ban on feminine appearance, despite the high importance that at least some of these women still attribute to a feminine visual representation ('I like to go out at night, I like to get dressed up' - Female civil engineer, 28 years old, participant 15). Such a 'sacrifice' of what is considered to be feminine and a recognition of the erotic and sexualised dimensions of femininity suggest that for these women, femininity is something that "exists" but that needs to be hidden in order to make their professional competence more noticeable.

\section{Assuming differences and inequalities}

The 'Assuming differences and inequalities' theme was used by only two of the participants. This theme describes an acknowledgement of differences between being a man and being a woman, and the recognition of the disadvantages women face in engineering. It also reveals contradictory positions held by men themselves:

"But we can see that, on one side, some, how can I say this, there is some special tenderness because we are ladies, but on the other hand, there's also some resistance in accepting our directives from a technical point of view.
It's more complicated when we have to be in charge [laughs]."

[Female civil engineer, 42 years old, participant 14]

As in previous excerpts, there seems to be a concern with treatment from men, although the emphasis is placed on situations of technical and leadership inequality. In addition, this participant clearly recognises the barriers women encounter when they try to fit in male-dominated social territories:

'Normally, in every negotiation there are several men and only one woman; then, there are those things that ... those intimacies that will never come up in a professional relationship between a man and a woman. It may happen, but it will be after many years, won't it?'

[Female geological engineer, 38 years old, participant 12]

The same respondent is also aware that engineering is an androcentric culture and even shows some pessimism regarding the possibility of changing women's positions in engineering:

'I feel that we are never going to be able to have the same relationship that men have between themselves in this sector, that women... no... we are never going to get there, at least in the near future.'

[Female geological engineer, 38 years old, participant 12]

According to this discourse, the professional relationships between men and women seem to be always marked by an affective-erotic dimension, which inhibits the development of professional relationships:

Well, we both go, we go there to the construction field, then we have lunch together and then, who knows, we even have dinner together. Then, you can't even imagine... Two married people... this is all professional, obviously, and... I have a lot of business dinners, dinners, also lunches, but we also have dinners and discotheques as well, if not discotheques, small bars or something like that.

[Female geological engineer, 38 years old, participant 12]

Accordingly, a professional meeting between two men, which can end up in a bar or a discotheque, cannot happen between a man and a woman:

'In the world of business everything counts and this is not a road we will take.'

[Female geological engineer, 38 years old, participant 12]

As this participant assumes that she is dealing with a male chauvinistic world, emphasising the importance of the context, she also concludes: 'but that's it, there is nobody to blame, it is the force of circumstances.'

The 'assuming differences and inequalities' position seems to be the only discursive strategy that affects women with a more feminine appearance ('I can sometimes wear tighter trousers, high heels...' - Female geological engineer, 38 years old, participant 12), suggesting an affirmative attitude in a predominantly masculine professional environment. Nonetheless, this discourse does not include a collectivistic perspective of women, or one of personal entitlement, although it denounces patriarchal 
attitudes, thus resembling a resistance discourse. This is the only position that clearly constructs women facing barriers in a male-dominated work environment, where their difficult position is equated without any subterfuges.

\section{Conclusion}

Our data suggests that women engineers adopt various strategies to make their femininity more invisible in order to give themselves more credibility in their professional lives, as also shown in previous research (e.g., Faulkner, 2009b; Jamieson, 1995; Jorgensen, 2002; Peterson, 2010). Only one of the discourses, used by only two of the participants, shows some distance from this positioning. Therefore, hegemonic masculinity sets the standard against which women engineers construct their identities.

It is important to notice that the discourses that were mostly used by female engineers are 'Maintaining limits and respect' and 'Disguising differences with similarities'. In these two positions, respondents subjectified themselves through the adoption of technologies of the self (Foucault, 1988) that focused on clothing, behaviour and language, the first technique separating men from women, while approximating them in the second. However, in 'Disguising differences with similarities', this positioning is assumed as something natural, internalised and, therefore, less premeditated. These women consider their similarities with men as something natural and stable because it happened early in their academic career and life and act as if this is a biological trait ('I was always more masculine', 'I always got along better with men'). In the 'Maintaining limits and respect' position, this process is more conscious and clearly used as a strategy for maintaining a feminine subject position. The word 'respect' seems to have a double meaning, which simultaneously includes erotic and professional dimensions. It is also important to stress that the strategy 'Disguising differences with similarities' involves a devaluation of characteristics socially attributed to women, as participants consider themselves special women and better than the others. They also deny discrimination and consider themselves equal to men.

The theme 'Assuming differences by valuing femininity' is a different case: women disclaim that they have qualities or attributes that are socially linked to femininity. Not frequently used by participants, this discourse seems to be the one that questions women's professional competence the most, as it makes femininity more visible. Consequently, the effects of this discourse are balanced by resorting to this discourse (I think that women have a better capacity for reaching consensus) simultaneously with the "Disguising differences with similarities" discourse (I blend easily in conversations, those everyday chats... the conversations about football. Their language has never affected me much, as well...), as demonstrated by participant number 4 (Female metallurgist engineer, 43 years old), who adapts her positions to the context. She reveals some flexibility, using both discourses, but also displays some ambiguity and conflict.

In the 'Assuming differences and inequalities' position, women recognise that there is gender discrimination in a society deemed as patriarchal. Nonetheless, they do not question the dominant ideology, nor do they enunciate resistance or change mechanisms. This discourse is not based on the essentialism of feminine or masculine characteristics, which allows for a conception of gender embedded in social interactions and the broader environment: 'those intimacies that will never come up in a professional relationship between a man and a woman' (Female geological engineer, 38 years old, participant 12), as mentioned in the work of Faulkner (2009a). This same respondent reinforces her perspective of men and women's relations at work, excusing society and men when she says "no one is to blame, it is the force of circumstances [laugh]" (although this laugh could be ironic). Another way to look at this discourse is that it repositions the debate as a social issue that affects everyone, men included.

Contrary to the resistance discourses found in the study also conducted in Portugal by Conceição Nogueira (2009) of women in politics, none of the discourses identified in this study suggests social change mechanisms or women's collectivistic activities. Nogueira's work was carried out with women in politics, which could have contributed to a higher degree of consciousness of equality issues. Thus, the results presented in this study seem to be more related to the contradictory positions that Jane Jorgensen (2002) found in her work.

In conclusion, women in engineering careers that participated in this study seem to regulate their behaviour and feelings through the internalisation of certain cultural prescriptions based on the power of hegemonic masculinity. Our results suggest that these women, although apparently free and successful, are, in fact, subjected to a regime that controls their behaviours and feelings with harmful consequences for their personal and relational well-being (Prilleltensky \& Nelson, 2002).

Resistance discourses and social movements would be reinforced by the recognition that the double binds of women's professional lives rely on a gender normativity based on hegemonic masculinity, which limits the affirmation of truly free subject positions for women and for men. The negotiation of masculinity is also a complex process: some men are accomplices of this type of masculinity, benefiting from the systematic subordination of women, but others also become subordinates, incapable of adjusting to the norm (Connell, 1995). However, according to Wheterell and Edley (1999), other subtle and diverse forms of masculinity may be in construction, and therefore it would be of interest to study the situations that bring out a more hegemonic form of masculinity that is in contradiction with other, more liberal, presentations of the self. We cannot be optimistic to the point of assuming that new forms of masculinity would be enough to facilitate the negotiation of women engineer's subjectivities, although the deconstruction of these double binds (and the capacity for understanding that the ways masculinity and femininity are presented as fixed and unalterable attributes are also forms of subjugation and exercises of power) may benefit women. In addition, contemporary hegemonic masculinity operates through increasingly complex and fragmented processes that harm not only women, but also the whole society, including men. Based on feminist perspective correlations between women and men, we agree with Lynne Segal (1990), who states that it is important to recognise the positive as well as the negative elements of social practices that construct men and masculinity. Transferring this idea to the field of engineering, we should insist in promoting changes in organisational practices and attitudes that may lead to the alteration of 
power between male and female engineers (Lee \& Faulkner, 2010).

On a final note, a change in women's representation and career progression in engineering is not only important for economic growth and development, as some literature asserts (European Commission, 2006), but also and above all is a matter of citizenship and human rights. When engineering organisational cultures exclude women or prevent them from progressing in their careers, significant human capital and critical mass is wasted and women's oppression is reinforced. Although in a different way, because the stigmatisation is not so evident, these women resemble other oppressed groups of women such as women of colour, disabled people, lesbians or women in political positions. Therefore, we borrow the panoptical image of Jeremy Bentham (Foucault, 1975), of a jail with transparent and unbreakable glass walls, to characterise engineering culture, which leaves everybody, but especially women, chained up, under public scrutiny, but most of all subjected to self-vigilance.

\section{References}

Amâncio, Lígia, \& Oliveira, João Manuel (2006). Men as individuals, women as a sexed category: Implications of symbolic asymmetry for feminist practice and feminist psychology. Feminism \& Psychology, 16(1), 36-44.

Arribas-Ayllon, Michael, \& Walkerdine, Valerie (2007). Foucauldian discourse analysis. In W. Stainton-Rogers, \& C. Willig (Eds.), Handbook of qualitative research in psychology (pp. 91-108). London: Sage.

Beauvoir, Simone (1989). The second sex. New York: Vintage Books.

Bouville, Mathieu (2008). On enrolling more female students in science and engineering. Science and Engineering Ethics, 14, 279-290.

Brotman, Jennie S., \& Moore, Felicia M. (2008). Girls and science: A review of four themes in the Science Education Literature. Journal of Research in Science Teaching, 45(9), 971-1002.

Cassell, Joan (2000). The woman in the surgeon's body. Cambridge, MA: Harvard University Press.

European Commission (2006). Women in science and technology - The business perspective. Brussels: European Commission.

Connell, R. W. (1995). Masculinities. Cambridge: Polity Press.

Connell, R. W. (2002). Gender. Cambridge: Polity Press.

Fassinger, Ruth E., Scantlebury, Kathryn, \& Richmond, Geraldine (2004). Career, family, institutional variables in the work lives of academic women in the chemical sciences. Journal of Women and Minorities in Science and Engineering, 10, 297-316.

Faulkner, Wendy (2000). Dualisms, hierarchies and gender in engineering. Social Studies of Science, 30(5), 759-792.

Faulkner, Wendy (2001). The technology question in feminism: A view from feminist technology studies. Women's Studies International Forum, 24(1), 79-95.

Faulkner, Wendy (2007). Nuts and bolts and people: gender-troubled engineering identities. Social Studies of Science, 37(3), 331-356.

Faulkner, Wendy (2009a). Doing gender in engineering workplaces cultures. I Observations from the field. Engineering Studies, 1(1), 3-18.

Faulkner, Wendy (2009b). Doing gender in engineering workplace cultures. II. Gender in/authenticity and the in/visibility paradox. Engineering Studies, 1(3), 169-189.

Foucault, Michel (1971). L'Ordre du discours, Leçon inaugurale ao Collège de France prononcée le 2 décembre 1970. Paris: Éditions Gallimard.

Foucault, Michel (1975). Surveiller et Punir: Naissance de la Prison. Paris: Éditions Gallimard.

Foucault, Michel (1984). An interview: Sex, power and the politics of identity. The Advocate, 400(7), 26-31.

Foucault, Michel (1985). The use of pleasure. London: Penguin Viking.

Foucault, Michel (1988). Technologies of the self. In L. H. Martin, H. Gutman, \& P. H. Hutton (Eds.), Technologies of the self (pp. 16-49). London: Tavistock.

Freenan, Dermot (2008). Women judges: Gendering judging, justifying diversity. Journal of Law and Society, 35(4), 490-519.

Frehill, Lisa (2009). The gendered construction of the engineering profession in the United States, 1893-1920. In M. E. Layne (Ed.), Women in engineering: Professional life (pp. 105-129). Reston: American Society of Civil Engineering.
Gilligan, Carol (1982). In a different voice: Psychological theory and women's development. Cambridge, MA: Harvard University Press.

Glick, Peter, \& Fiske, Susan T. (2001). Ambivalent sexism. In M. P. Zanna (Ed.), Advances in experimental social psychology, 33. (pp. 115-188). San Diego: Academic.

Glynn, R. W., \& Kerin, M. J. (2010). Factors influencing medical students and junior doctors in choosing a career in surgery. The Surgeon, 8, 187-191.

GPEARI (2009). Diplomados no Ensino Superior [2000-2001 a 2007-2008]. Lisboa: Gabinete de Planeamento, Estratégia, Avaliação e Relações Internacionais.

Grant, Valerie J., Robinson, Elisabeth, \& Muir, Paul (2004). Sex ratios in healthcare occupations: Population based study. British Medical Journal, $328,141-142$.

Hinze, Susan W. (2004). 'Am I being over-sensitive?' - Women's experience of sexual harassment during medical training. Health: An Interdisciplinary Journal for the Social Study of Health, Illness and Medicine, 8(1), 101-127.

Jamieson, Kathleen Hall (1995). Beyond the double bind: Women and leadership. New York: Oxford University Press.

Jorgensen, Jane (2002). Engineering selves: Negotiating gender and identity in technical work. Management Communication Quarterly, 15(3), 350-380.

Kelan, Elisabeth K. (2007). 'I don't know why' - Accounting for the scarcity of women in ICT work. Women's Studies International Forum, 30, 499-511.

Kendall, Lori (2000). "Oh no! I'm a nerd!" Hegemonic masculinity on an online forum. Gender and Society, 14(2), 256-274.

Lee, Lisa, \& Faulkner, Wendy (2010). Turning good policies into good practice: Why is it so difficult? International Journal of Gender, Science and Technology, 2, 1 .

Leon, Maria Antonia (1994). Elites Discriminadas: Sobre o poder das Mulheres [Discriminated elites: On the power of women]. Barcelona: Anthropos.

Marques, António Manuel (2011). Profissões Masculinas: Discursos e Resistências [Male professions: Discourses and resistances]. Lisboa: Fundação Calouste Gulbenkian.

Martin, Patricia Y., Reynolds, John R., \& Keith, Shelley (2002). Gender bias and feminist consciousness among judges and attorneys: A standpoint theory analysis. Signs: Journal of Women in Culture and Society, 27(3), 665-701.

Martínez Reina, Maria Carmen, \& Cea, Manuel Vélez (2006). Valores de género en la educación de niñas y niños. Los juegos y juguetes [Gender values in girls and boys education. Games and toys]. Meridiam, 38, 52-55.

Mills, Julie E., Gill, Judith, Sharp, Rhonda, \& Franzway, Suzanne (2011). Getting it together: Feminist interdisciplinary research on women and engineering. Women's Studies International Forum, 34, 13-19.

Nogueira, Conceição (2009). Women in positions of power in Portugal: Contradictory positions and discourses. Journal of Women, Politics E Policy, 30(1), 70-88.

Oldenziel, Ruth (1999). Making technology masculine: Men, women and modern machines in America, 1870-1945. Amsterdam: Amsterdam University Press.

Oliveira, João Manuel, \& Amâncio, Lígia (2002). Liberdades condicionais: O conceito de papel sexual revisitado [Conditional liberties: The concept of sex role revisited]. Sociologia, Problemas e Práticas, 40, 45-61.

Parker, Ian (1992). Discourse dynamics: Critical analysis for social and individual psychology. London: Routledge.

Parker, Ian (1999). Varieties of discourse and analysis. In I. Parker, \& the Bolton Discourse Network (Eds.), Critical textwork: An introduction to varieties of discourse and analysis (pp. 1-13). Buckingham: Open University Press.

Peterson, Helen (2010). The gendered construction of technical self-confidence: Women's negotiated positions in male-dominated, technical work settings. International Journal of Gender, Science and Technology, 2, 1.

Prilleltensky, Isaac, \& Nelson, Geoffrey (2002). Doing psychology critically: Making a difference in diverse settings. New York: Macmillan Press.

Saavedra, Luísa, \& Nogueira, Conceição (2006). Memórias sobre o feminismo na psicologia: para a construção de memórias futuras [Memories about feminism in psychology: building future memories]. Memorandum, 11, 113-127.

Segal, Lynne (1990). Slow motion: Changing masculinities, changing men. London: Virago.

Wajcman, Judy (2000). Reflections on gender and technology studies: In what state is the art? Social Studies of Science, 30(3), 447-464.

Watts, Jacqueline H. (2009). Leaders of men: Women 'managing' in constructions. Work, Employment \& Society, 23(3), 512-530.

Wheterell, Margeret, \& Edley, Nigel (1999). Negotiating hegemonic masculinity: Imaginary positions and psycho-discursive practices. Feminism \& Psychology, 9(3), 335-356.

Willig, Carla (2003). Discourse analysis. In J. A. Smith (Ed.), Qualitative psychology: A practical guide to research methods (pp. 159-183). London: Sage.

Willig, Carla (2008). Foucauldian discourse analysis. In C. Willig (Ed.), Introducing qualitative research in psychology (pp. 112-131). London: Open University Press. 